\section{The fish that time forgot}

\author{
Michael A. Taylor
}

Living Fossil: The Story of the Coelacanth. By Keith Stewart Thomson. Norton/Radius: 1991. Pp. 252. \$19.95, £15.99.

THERE are indeed special reasons for the worldwide fascination with the 'living fossil' fish Latimeria chalumnae, better known as the coelacanth. All the same, I am sure Keith Thomson suffers from the coelacanth strain of the syndrome that afflicts my research on plesiosaurs. Any mention of these extinct marine reptiles too often triggers an enquiry about the Loch Ness monster. With age and wisdom, I no longer damn the Scottish Tourist Board, but instead discuss the plausibility of Nessiteras. This is a surprisingly severe test of anyone's knowledge of plesiosaurs, and gives the layperson a demonstration of science in messy action. And, not least, it wins half the battle by capturing the audience's attention from the start.

Thomson has the same advantage, with the added benefit that biologists have managed to catch living coelacanths, although they are still at a loss to explain why the fish should exist at all. This enjoyable look at coelacanths will suit almost everyone from interested laics, through students wanting background reading, to any zoologist or geologist who is not a sarcopterygian specialist.

Thomson's measured and understated, but still personal, style has been honed in the essay column of American Scientist, and is a refreshing contrast to the personal aggrandizement and even backbiting of some other writers on evolution and fossils. He does not expand unduly on his own research. When he tells how he obtained the first frozen coelacanth (much more imformative than the pickled version) by simply asking the Comoran government for it, he can only wonder at his naivety.

The first-recorded catch of the coelacanth was made off the coast of southern Africa in 1938. The discovery was announced in a short notice to Nature, albeit not without being scooped by the London Illustrated News. Disputes continued with the capture of the second specimen off the remote Comoro Islands, then the territory of the French government, who claimed a legal right to the fish. After the capture of the third specimen in 1953, the French declared a complete ban on expeditions in the area by foreign scientists, which was not lifted until the end of French colonial rule some 15 years later. There was even a ban on dissecting any specimens sent to foreign museums.

The key discoveries were made by people who were unsupported by conventional science funding, but who nevertheless knew an opportunity when they saw one: Marjorie CourtenayLatimer, who, as curator of a tiny museum in Cape Province, South Africa, discovered the fish, recognizing it as something odd; J. L. B. Smith, the chemistry lecturer and spare-time ichthyologist who identified it as a coelacanth and wrote the paper to Nature; and Hans Fricke who raised private cash

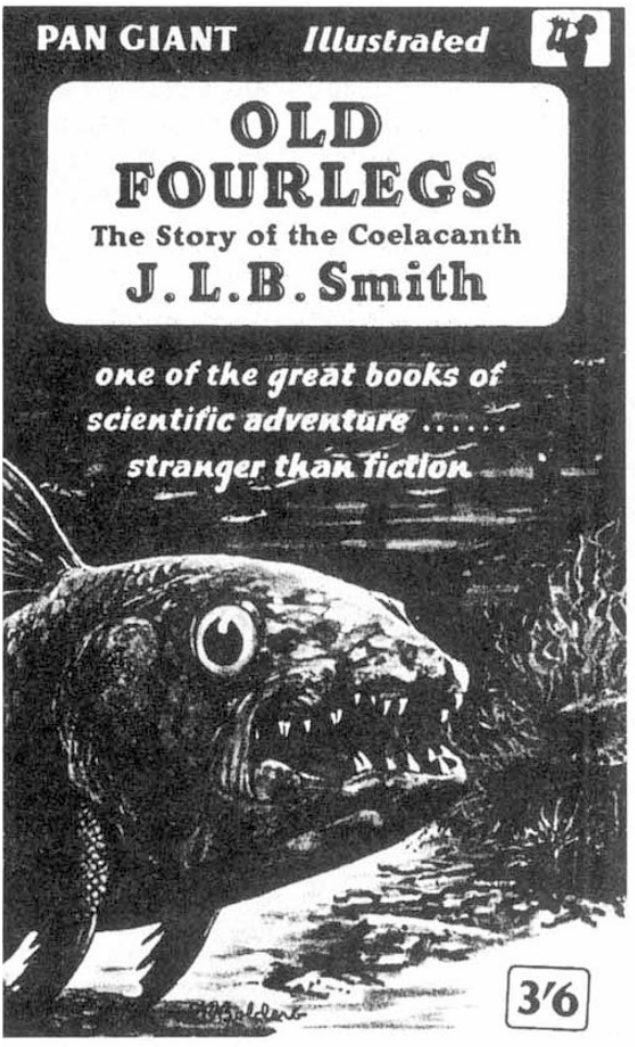

The cover of J. L. B. Smith's popular book (1956). The picture is one of many in The Biology of Latimeria chalumnae and evolution of coelacanths (eds J. A Musick, M. N. Bruton and E. K. Balon), the largest and most comprehensive volume so far published on the fish. Published by Kluwer, price is Dfl. $350, \$ 199$, $£ 177.50$.

for his Submarine photographic observations. But they lived in relative wealth compared with the fishermen such as Ahmed Hussein Bourou who did the hard work from tiny pirogues with handlines hundreds of metres long. Today there is practically uncontrolled exploitation of coelacanth fishing by the now independent and desperately poor Comorans.

This is not a book of academic minutiae, whether about the history of science or fish evolution. Thomson seems to have decided that detail such as the new Greenland fossil tetrapods is irrelevant to the central theme of the coelacanth, how it lives and breeds, and why it is there. A few more illustrations and labels in the book might have helped explain matters such as notochords and humeral homologies, but most readers will get enough succinct grounding in topics such as the nature of living fossils, continental drift, the origin of tetrapods, and taxonomy, to appreciate Latimeria's significance. I certainly came away fully appreciating that the many gaps in our knowledge of Latimeria's lifestyle are nothing compared with the puzzle of how it apparently came to live only in the impoverished habitat of a few underwater lava slopes. Moreover, these slopes have existed for merely a fraction of the roughly 70 million years that separate the fish from the last-known fossil coelacanths.

Thomson reveals the humanity of scientists and the fallibility of memory. Nevertheless, his hero remains Latimeria, so read the book, then watch Fricke's extraordinary documentaries of coelacanths in the wild. In these, Latimeria, like Lewis Carroll's Father William, comes across as an old if sometimes inscrutable member of the family. The two share many traits: Latimeria will incessantly stand on its head, keeps all its limbs very supple and swears by large amounts of oil, at least for buoyancy control. But instead of balancing an eel on its nose, it has the amazing, apparently electroreceptive rostral organ. Despite the coelacanth's nickname of 'old fourlegs', its remarkably mobile paired fins are a drift-hunter's means of staying on station in a slow current, rather than the bottom-crawling fins of tetrapod ancestors. So 'father' seems purely honorific. As Thomson stresses, Latimeria is "not trying to be an amphibian or an amphibian trying to be a fish. It is a perfectly good fish.

Unfortunately, Latimeria may never recover from our obsessive interest in our close relative (but, as Thomson points out, not that close)

As J. L. B. Smith long ago feared, its slow reproductive rate and our utter ignorance of its true population size mean that every capture of a female whether for research, commercial exhibition or tourist souvenir — could be driving the species to extinction. Captive breeding might well destroy, and will at least alter, the very species it aims to save. Leave the fish alone, Thomson says, for if Latimeria becomes extinct, there really will be no one else to blame but us scientists.

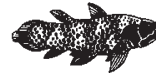

Michael Taylor is in the Earth Sciences Section, Leicestershire Museums, Arts and Records Service, 96 New Walk, Leicester LE1 6TD, UK. 